\title{
A Review of Bactrocera minax (Diptera: Tephritidae) in China for the Purpose of Safeguarding
}

\author{
Yulu Xia ${ }^{*}$, Xingli $\mathrm{Ma}^{1 *}$, Bohua Hou${ }^{2}$, Gecheng Ouyang² \\ ${ }^{1}$ NSF Center for Integrated Pest Management, North Carolina State University, Raleigh, NC, USA \\ ${ }^{2}$ Guangdong Key Laboratory of Animal Conservation and Resource Utilization, Guangdong Public Laboratory of Wild Animal \\ Conservation and Utilization, Guangdong Institute of Applied Biological Resources, Guangzhou, China \\ Email: *yuluxia@cipm.info, *xinglima@cipm.info, houbohua@giabr.gd.cn,18922369378@189.cn
}

How to cite this paper: Xia, Y., Ma, X.L., Hou, B.H. and Ouyang, G.C. (2018) A Review of Bactrocera minax (Diptera: Tephritidae) in China for the Purpose of Safeguarding. Advances in Entomology, 6, 35-61.

https://doi.org/10.4236/ae.2018.62005

Received: January 4, 2018

Accepted: March 12, 2018

Published: March 15, 2018

Copyright $\odot 2018$ by authors and Scientific Research Publishing Inc. This work is licensed under the Creative Commons Attribution International License (CC BY 4.0).

http://creativecommons.org/licenses/by/4.0/

\begin{abstract}
The Chinese citrus fly, Bactrocera minax (Enderlein) (Diptera: Tephritidae), is the most destructive citrus pest in many citrus production areas in China. The pest is oligophagous, feeding exclusively on the fruits of citrus plants. The pest is univoltine, with adults emerging during April to May and overwintering as pupae. Evidence suggests that the region of origin of the species might be in the elevated temperate southern Yunnan-Guizhou Plateau, spreading out through China's major waterway systems. Currently, B. minax occurs in nine citrus producing provinces in China, but mostly prominently in the five south central provinces or municipalities of Guizhou, Hubei, Hunan, Sichuan, and Chongqing. Fruit infestations in these provinces are generally moderate to severe. The species is not reported in the four southern citrus production provinces of Guangdong, Fujian, Zhejiang, and Hainan (island). Orchard sanitation such as collection and treatment of the fallen and hanging infested fruits, mass trapping by using various food-based traps with insecticides, and foliar and ground insecticide sprays are the primary pest management options. Sterile insect technology was studied in the field in the 1980s to 1990s, with promising outcomes. The two highly attractive kairomone lures used for many Bactrocera species, cuelure or methyl eugenol, are not attractive to this species. Hydrolyzed protein, sugar and vinegar mixture, and waste brewer's yeast are the most common lures being used in China. Published data indicated that the quality and efficacy of these lures are inconsistent and disputable. Visual cue lures such as colored sticky spheres are also being used in the field. Preliminary field studies suggested that female rectum extracts demonstrated high attraction to males as well as females of the species. Phytosanitary treatment studies in China focus on irradiation and cold treatment. The outcomes of irradiation appeared promising. When B. minax larvae were treated
\end{abstract}


with an irradiation dose of $50 \mathrm{~Gy}$, no adults emerged from the surviving pupae and larvae failed to pupate when the dose reached $70 \mathrm{~Gy}$. No fruit quality was impacted by the treatment. Results from several small-scale cold treatment studies were less promising and inconsistent. One study indicated that under $0^{\circ} \mathrm{C}$ constant treatment, no mortality of 3rd instar larvae occurred until day 12 , and only $55 \%$ mortality occurred by day 22 . The scientific and technological gaps in safeguarding US citrus industry from the invasion of this destructive pest include: 1) lack of effective lures for early detection and emergency responses; 2) insufficient work on phytosanitary treatment techniques; and 3) weak definition of and lack of data for $B$. minax pest free areas in China.

\section{Keywords}

Chinese Citrus Fly, Citrus, Phytosanitary, Risk

\section{Introduction}

The Chinese citrus fly, Bactrocera minax (Enderlein), is the most destructive citrus pest in many groves in south-central China. The pest can cause up to $100 \%$ fruit damage in severe situations [1]-[8]. B. minax also occurs in limited regions of Bhutan and Northwest India bordering with China [3].

Interest in this pest outside of China has risen in recent years. This is primarily due to the concern that $B$. minax might spread to the world's other major citrus production regions through fresh fruit trade and travelers. China has already exported a large volume of fresh citrus fruits to a number of countries in Asia, Russia, Europe, and the Americas [9]. Mexico just recently approved China fresh citrus fruits market access [10]. It appears that fresh citrus fruits from China will likely reach US markets in the near future [11] [12] [13] [14]. To prevent this severe pest from spreading to other countries, sound knowledge of the pest is critical for pest safeguarding works.

Laboratory and field studies of the pest have been carried out in China since the early part of the last century. However, results of these works were almost exclusively published in Chinese journals, with few exceptions [15]-[24]. Several Chinese review papers on the pest were published recently [3] [25] [26] [27]. Besides the language issue, these review papers are generally brief, falling short of a comprehensive review about the pest, especially in the safeguarding areas such as pest detection, monitoring, and phytosanitary measures. The goal of this review is to fill this gap. Specifically, this paper has two major objectives: 1) to provide readers with a comprehensive review of current understandings of this pest, focusing on the areas of pest safeguarding; and 2) to highlight some of the critical scientific and technological gaps in protecting the US citrus industry from the potential invasion of this destructive pest. Since several papers in English have good coverage on the basic biology and ecology of B. minax [16]-[21] [24] [28], this paper will be brief on these areas. 


\section{Life Cycle and Biology}

B. minax has several biological characteristics that separate this species from the vast majority of species in the genus Bactrocera. First, B. minax is univoltine; second, the species is oligophagous, exclusively feeding on citrus plants; third, the pest is large in size, larvae can be as long as $16 \mathrm{~mm}$, adults can reach as long as $24 \mathrm{~mm}$ [29]; and lastly, B. minax is among the most cold tolerant species in the genus, with larvae able to survive freezing temperatures for days [30] [31].

The life cycle of $B$. minax is well studied in China. Adults start to emerge in April across most occurrence regions (Table 1). Adults live from one to three months, with life cycles ending in late June to July in most regions [2] [3] [32] [33] [34]. After emerging, adults fly to nearby woods feeding on such items as honeydew secreted by aphids [35]. By the second to third week, adults reach sexual maturity and start mating [21]. Females lay eggs 15 days or so after mating [4] [33]. The insect prefers laying eggs in young fruits with diameters of 2 to $4 \mathrm{~cm}$ [34] [36] [37] [38] [39]. The number of eggs laid per female varies from 50 to more than 200 eggs [2] [32] [34]. It appears that adults prefer laying eggs on sweet orange to other citrus fruits [32] [40]. The egg stage lasts roughly one month. Larvae feed inside the fruits until maturity (3rd instar). The mature

Table 1. The life cycle of $B$. minax in major citrus production province of China.

\begin{tabular}{|c|c|c|c|c|c|c|c|c|c|c|c|c|c|c|}
\hline \multirow{2}{*}{ Province } & \multirow{2}{*}{ Stage } & \multicolumn{12}{|c|}{ Month } & \multirow{2}{*}{ References } \\
\hline & & J & F & M & A & M & $\mathrm{J}$ & J & A & $S$ & $\mathrm{O}$ & $\mathrm{N}$ & $\mathrm{D}$ & \\
\hline \multirow[t]{4}{*}{ Hunan } & Adult & & & & & & & & & & & & & [53] \\
\hline & Egg & & & & & & & & & & & & & [39] \\
\hline & Larva & & & & & & & & & & & & & [25] \\
\hline & Pupa & & & & & & & & & & & & & [53] \\
\hline \multirow[t]{4}{*}{ Shaanxi } & Adult & & & & & & & & & & & & & [99] \\
\hline & Egg & & & & & & & & & & & & & [58] \\
\hline & Larva & & & & & & & & & & & & & [99] \\
\hline & Pupa & & & & & & & & & & & & & [99] \\
\hline \multirow[t]{4}{*}{ Hubei } & Adult & & & & & & & & & & & & & {$[5]$} \\
\hline & Egg & & & & & & & & & & & & & [4] \\
\hline & Larva & & & & & & & & & & & & & [100] \\
\hline & Pupa & & & & & & & & & & & & & [68] \\
\hline \multirow[t]{4}{*}{$\begin{array}{c}\text { Sichuan } \\
\text { Chongqing }\end{array}$} & Adult & & & & & & & & & & & & & [101] \\
\hline & Egg & & & & & & & & & & & & & [95] \\
\hline & Larva & & & & & & & & & & & & & {$[6]$} \\
\hline & Pupa & & & & & & & & & & & & & [6] \\
\hline
\end{tabular}


larvae fall from hanging fruits or exit from fallen fruits into soil for overwintering. The larval stage lasts roughly two months. The pupal stage is the longest stage of the species, lasting from 150 to almost 200 days [3] [32] [33]. Most pupae overwinter in the soil at a depth of $4-6 \mathrm{~cm}$ [3] [4] [33]. Scientists in China generally agree that pupae go through a weak diapause [19] [27] [31] that requires some cold temperature threshold exposure to break the diapause [19] [31]. Topical application of hormone 20-hydroxyecdysone can terminate the diapause process [23].

\section{Distribution of $B$. minax}

B. minax occurs in nine citrus production provinces in China (Figure 1). However, the severity and economic impact of the pest can vary extremely among these provinces. Accordingly, the occurrence area of B. minax in China can be grouped into three regions (Common, Moderate, and Low). It is worth mentioning that since there is no domestic pest survey program like the United States Department of Agriculture (USDA) Cooperative Agricultural Pest Survey (https://caps.ceris.purdue.edu/home) in China, the pest distribution discussed here is largely based on published papers.

\subsection{Common Occurrence Region}

Areas in China where B. minax is widely occurring and causes significant economic damage to citrus include the following provinces and/or municipalities:

Guizhou. B. minax has been reported in all citrus production areas in the province [3] [26] [41] [42] [43]. Chinese scientists believe that Yunnan-Guizhou Plateau is likely the original home to this species, based on its occurrence history and pattern of spread [26].

Sichuan. Sichuan is one of China's major citrus growing provinces. Similar to Guizhou, B. minax has a long occurrence history in Sichuan province [3] [6] [26] [44] [45] [46]. The earliest report of the pest was from the 1850s [7] [47] and by the 1950s, B. minax was found in all major citrus production regions. Sichuan borders northward with the Yunnan-Guizhou Plateau.

Chongqing. Administratively, this central government direct-controlled municipality city was a part of Sichuan province until 1997. As discussed above, $B$. minax has widely occurred in Sichuan since the 1950s and accordingly, the pest is common in the municipality of Chongqing as well. The pest is particularly prevalent in the citrus production area near the Three Gorges Dam [3] [26] [48] [49].

Hubei. Hubei is another major citrus growing province in China. B. minax occurs commonly throughout the province [3] [5] [26] [48] [50] [51].

Hunan. Hunan is China's number one citrus growing province based on annual fruit production [52]. B. minax was found in all production regions, with various levels of severity [3] [26] [48] [53]. Generally speaking, the occurrence is more severe in moderately elevated (200 to $600 \mathrm{~m}$ ASL) locations. 


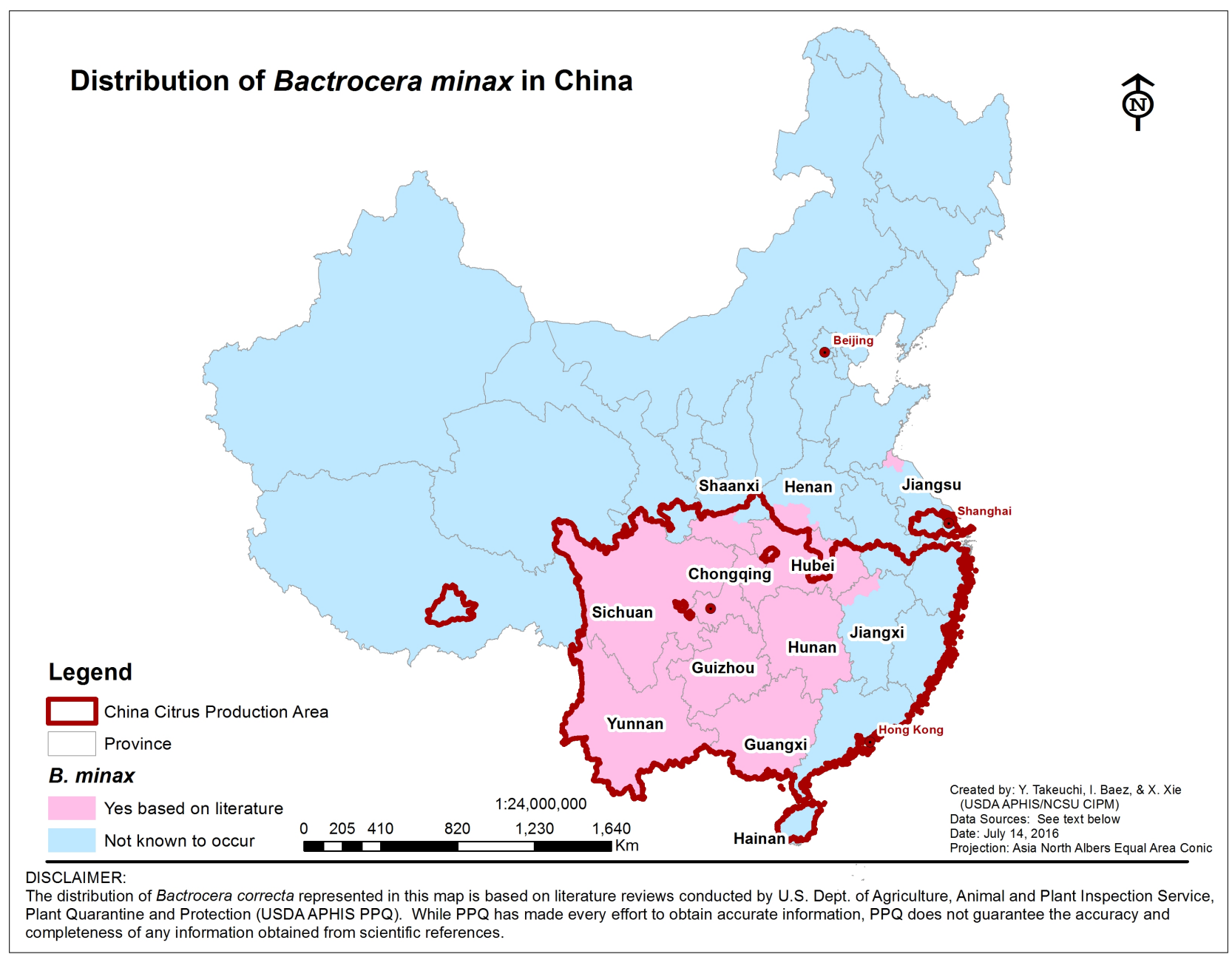

Figure 1. B. minax distribution in China.

\subsection{Moderate Occurrence Region}

Areas of China where B. minax is present but occurs in limited areas with moderate to low population levels and where economic damage to the citrus industry is correspondingly moderate to low, include the following provinces:

Yunnan. Although Yunnan-Guizhou Plateau is believed to be the original home of this species, $B$. minax is mainly found in the northeast regions bordering with Guizhou province [3] [48]. A recent 2-year-study in Dali, a western region of the province, found no B. minax present (Ouyang, unpublished data), which supports the claim that the pest might have a limited distribution there.

Guangxi. Although B. minax has been reported from Guangxi province since the 1950s, the economic damage and distribution area appear moderate [48] [54]. The area where occurrence is more common is in the northern citrus production area, bordering with Hunan and Guizhou.

Shaanxi. Shaanxi is the northern most citrus producing province in China. The province is at similar latitudes as Oklahoma in US B. minax can be commonly found in areas around Hanzhong, the province's major citrus production region [26] [48] [55] [56] [57] [58] [94]. As citrus acreage expands rapidly in the 
province, $B$. minax occurrence might become more severe.

Jiangxi. Jiangxi is China's major sweet orange production province. However, citrus production has been severely impacted by the outbreak of huanglongbing (citrus greening) in recent years. B. minax occurs in the northern region of Jiujiang [3] [26].

\subsection{Low Occurrence Region}

Henan and Jiangsu Provinces have reported occurrences of $B$. minax, however, the pest was either eradicated or disappeared itself [3] [26] [48] [59]. These two provinces have very limited citrus production.

According to existing data, B. minax is not reported in four southern coastal citrus production provinces: Guangdong, Fujian, Zhejiang, and Hainan Island. No study has been conducted to explore why $B$. minax does not occur in these provinces [3]. Temperature might be the primary factor. B. minax appears to be a temperate tephritid species, whose biology is more closely related to Rhagoletis species than other Bactrocera. The known geographical distribution of $B$. minax in China is in the areas between 24 - $33 \mathrm{~N}$ latitude, usually $230-1500 \mathrm{~m}$ in altitude [3] [48]. The warm winters and hot humid summers in Fujian, Guangdong, and Hainan may limit B. minax presence. It is not sure whether interspecific competition plays any role here or not [60] [61]. Due to different food niche and host preference, it is very unlikely that any competition exists between $B$. minax and $B$. tau as well as $B$. curcubitae, two common tephritid fruit flies occur in southern China. The interspecific relationships between B. minax and B. dorsalis, the most destructive and predominant fruit fly in southern China, is more complex than with other tephritid species. Although both species feed on citrus fruits, $B$. dorsalis is a polyphagous species, prefers laying eggs on the maturing fruits, whereas $B$. minax feeds Citrus fruits only, prefers laying eggs on young fruits as stated earlier.

\section{A Brief on the Region of Origin and Spread of B. minax}

It is our opinion that Yunnan-Guizhou Plateau is likely the region of origin for B. minax for the following three reasons. First, $B$. minax appeared widely distributed in the mountainous Guizhou province long before other places in China [26] [47]. Chinese literature more than 1000 years ago described citrus fruit maggots and fruit fly field occurrence in Guizhou and Hubei [3] [26] [47]. Since few damaging fruit flies are ever reported in the region other than $B$. minax, it seems reasonable to assume that the fruit fly described in the literature was $B$. minax. Second, B. minax is exclusively a citrus plant pest. Yunnan-Guizhou Plateau is believed to be one of the original places of contemporary citrus species [62] [63]. Third, according to studies, before the 20th century the pest was primarily spread by the waterway systems (i.e. rivers) [26]. Several high mountain peaks of Yunnan-Guizhou Plateau are the source of many great rivers in Asia, including China's two largest rivers, Yangtze and Yellow River, as well as the 
Mekong (also known as the Lancang) and Salween Rivers, which run into other countries in Southeast Asia (Figure 2). This might explain why neighboring provinces such as Hubei, Hunan, and Sichuan also have a long history of the pest occurrence, as well as its occurrence in the Kingdom of Bhutan and northwest India.

Further discussion of the possible region of origin of $B$. minax is beyond the purpose of this writing. However, knowledge of the pest's origin can be critical in the development of a pest risk assessment and other safeguarding efforts. For example, Yunnan-Guizhou Plateau is a typical moderate climate region in spite of its low latitude location. Average high temperatures during July in Yunnan are about $25^{\circ} \mathrm{C}$, vs. $34^{\circ} \mathrm{C}$ in Orlando, Florida (Figure 3), US whereas the climate of China's southern coastal region is similar to Florida. As discussed above, China's coastal citrus region has no $B$. minax reported so far. There are few restrictions on the movement of fresh fruits, either by vehicles or travelers in China. Therefore, we may speculate that $B$. minax might have reached its natural limit of geographical distribution within China and similarly speculate that the climate in Florida might not be a good match for this pest.

\section{Field Infestation and Severity}

Although B. minax has a long history of occurrence in China, the pest didn't have widespread economic impact until recent decades. Three factors contributed to the change in pest status. First, citrus growing acreage in China has experienced dramatic expansion in recent decades. For the period of 1949 to 2008, China's citrus production area and fresh fruit yield rose 62.2 and 103.8 fold, respectively, vs. world averages of 7.3 and 6.7 fold for the same period [64]. The

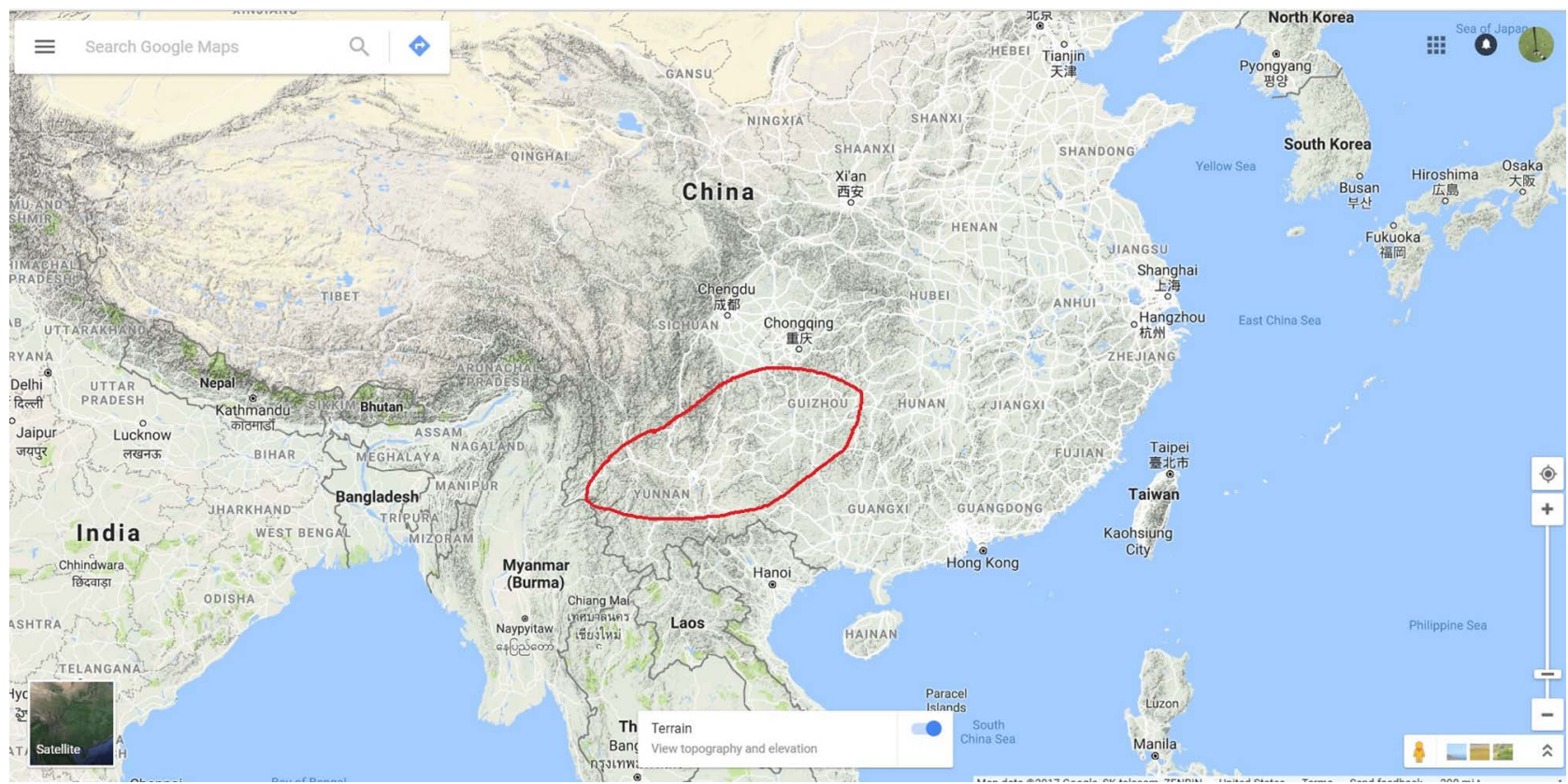

Figure 2. Yunnan-Guizhou plateau, china. 


\section{Orlando}

Max, Min and Average Temperature $\left({ }^{\circ} \mathrm{C}\right)$

$\begin{array}{lllllll}\text { Zoom } 1 \mathrm{~m} & 3 \mathrm{~m} & 6 \mathrm{~m} & \text { YTD } & 1 \mathrm{y} \quad \text { All }\end{array}$
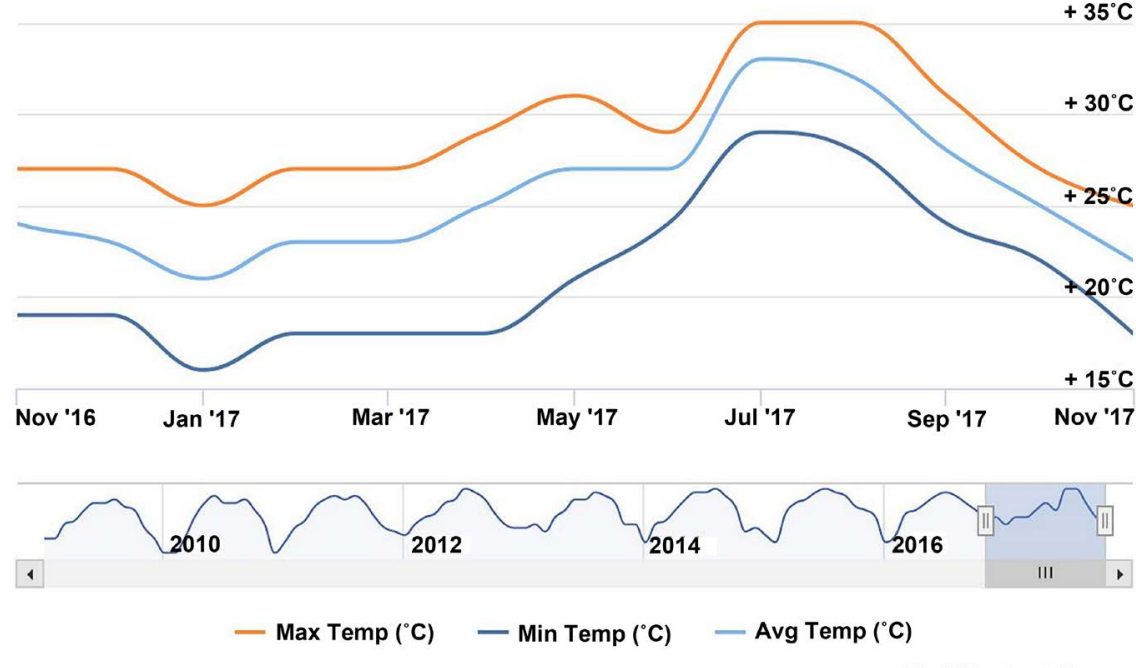

(a)

Yunnan, China

Max, Min and Average Tem[erature $\left({ }^{\circ} \mathrm{C}\right)$

Zoom $1 \mathrm{~m} \quad 3 \mathrm{~m} \quad 6 \mathrm{~m} \quad$ YTD $1 \mathrm{y} \quad$ All

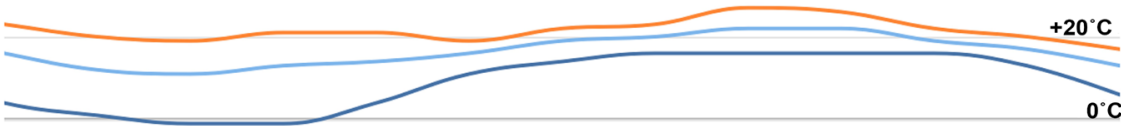

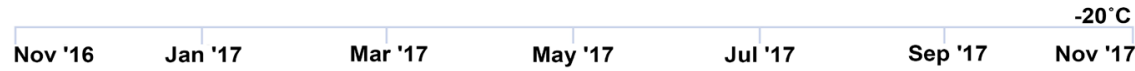

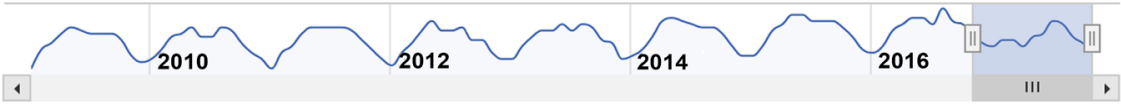

$-\operatorname{Max} \operatorname{Temp}\left({ }^{\circ} \mathrm{C}\right) \quad-\operatorname{Min} \operatorname{Temp}\left({ }^{\circ} \mathrm{C}\right) \quad$ Avg Temp ( $\left.{ }^{\circ} \mathrm{C}\right)$

WorldWeatherOnline.com

(b)

Figure 3. Average high/low temperature in Yunnan (right), China, in comparison to Orlando, Florida (left), US (credit:

http://www.worldweatheronline.com/orlando-weather-averages/florida/us.aspx).

majority of the production expansion occurred in the south-central region such as in Hubei and Hunan, where B. minax commonly occurs. Second, changes in China's agricultural production system occurred in the late 1970s to the early 1980 s that disrupted area-wide pest management programs. The previously large collective-owned orchards were replaced with small-scale (usually less than 0.3 ha), family-owned orchards. This change made it much more challenging to 
coordinate and enforce pest management activities. Third, weak domestic pest quarantine and inspection efforts failed to stop the spread of this pest. There was essentially no domestic quarantine and inspection in China before 1950 and even today the system is unreliable. B. minax, has not been on China's quarantine pest list since 2009 [65].

Theoretically, both trapping and fruit infestation data are good indicators of pest severity. However, due to the fact that there is no effective trap for the pest, as we will discuss later, negative trapping data for this pest can be misleading. Fruit infestation might be the only reliable indicator of pest severity in the case of $B$. minax. Table 2 summarizes the data from six provinces.

Guizhou. Fruit infestation by $B$. minax in the province varied widely, from less than 1 to $100 \%$. The Plant Protection Station of Guizhou Province conducted a province-wide survey from 1994 to 1996 . Among 6080 ha surveyed, $B$. minax occurred in 4180 ha, accounting for $68.8 \%$ of the surveyed area. A total of 55 counties in the province had B. minax occurrence. Zunyi region had an average of $20 \%-40 \%$ fruits infested [35] [66].

Hubei. B. minax occurrence in Hubei is more severe than Guizhou, based on the data of infested fruits. Most surveys indicated $20 \%$ or higher of fruits infested.

Hunan. Hunan is another severe B. minax occurring province. A recent survey by [53] showed more than $50 \%$, and up to $100 \%$ fruit infestation in some groves. Our recent field trips to the province indicated that in the well-managed groves such as most citrus orchards in Shimen County, fruit infestation usually falls under $1 \%$.

Sichuan. As discussed above, Sichuan has a long history of $B$. minax occurrence. The most notorious outbreak of $B$. minax in recent China's history occurred in Guangyuan region of the province. The severity of the outbreak was unprecedented; few fruits in the entire region were saved from B. minax infestation [6] [46]. Unfortunately, few data are publically available, but limited survey data indicated $20 \%-30 \%$ of fruits were infested with $B$. minax (Table 2).

Henan and Shaanxi. These two provinces have very limited citrus production areas. B. minax was reported to cause various degrees of fruit damages.

\section{Host \& Host Preference}

Table 3 lists the citrus host plants reported in Chinese literature. It appears that all Citrus cultivated species and cultivars in China are hosts of $B$. minax. Other documented hosts of $B$. minax in family Rutaceae include trifoliate orange (Poncirus trifoliata), a common rootstock used in citrus grafting, and kumquat, Fortunella margarita.

Strong scientific evidence suggests that $B$. minax prefers navel oranges and/or other sweet orange cultivars [32] [39] [67] [68]. Table 4 lists field survey data, comparing B. minax fruit infestation rates on citrus species/varieties. Navel orange and other sweet oranges consistently showed the highest fruit infestation rates. However, one field survey indicated that B. minax preferred pomelo, 
Table 2. Field fruit infestations by $B$. minax.

\begin{tabular}{|c|c|c|c|}
\hline $\begin{array}{l}\text { Province/Survey } \\
\text { Year(s) }\end{array}$ & $\begin{array}{l}\text { Host-Common Name/ } \\
\text { scientific name }\end{array}$ & $\%$ infested & References \\
\hline Guizhou/1986-1988 & Pomelo/Citrus maxima & 71.4 & [35] \\
\hline Guizhou/1986-1988 & $\begin{array}{c}\text { Sweet orange/Citrus sinensis } \\
\text { Osbeck }\end{array}$ & 1.7 & {$[35]$} \\
\hline Guizhou/1986-1988 & $\begin{array}{l}\text { Bitter orange/ Citrus } \\
\text { aurantium } \mathrm{L} .\end{array}$ & 0.7 & [35] \\
\hline Guizhou/1960s-1970s & Citrus spp. & Avg. 20 & [1] \\
\hline Guizhou/1980s & Citrus spp. & Avg. $5-8$ & [1] \\
\hline Guizhou/1987 & Citrus spp. & $5-8$ & [43] \\
\hline Guizhou/1995 & Citrus spp. & 11.9 & [102] \\
\hline Guizhou/1994-1996 & Citrus spp. & $20-40$ & {$[66]$} \\
\hline Guizhou/1990s & Citrus spp. & Avg. $70-80$ up to 100 & {$[42]$} \\
\hline Hubei/1980-1987 & Citrus tangerina & $\begin{array}{c}30 \text { (early mature varieties); } 5 \\
\text { (late mature varieties) }\end{array}$ & [2] \\
\hline Hubei/1980-1987 & $\begin{array}{l}\text { Sweet orange/Citrus } \\
\text { sinensis Osbeck }\end{array}$ & $40-78.9$ & [2] \\
\hline Hubei/1980-1987 & Pomelo/Citrus maxima & $40-78.9$ & [2] \\
\hline Hubei/1980-1987 & $\begin{array}{c}\text { Medicinal Citron/Citrus } \\
\text { medica L. }\end{array}$ & $40-78.9$ & [2] \\
\hline Hubei/1990s & Citrus spp. & Ave. 10 - 20; severe 60 - 90 & [4] \\
\hline Hubei/1995 & Citrus spp. & Ave. 30 - 50; up to 90. & [5] \\
\hline Hubei/2006 & $\begin{array}{l}\text { Sweet orange/ Citrus } \\
\text { sinensis Osbeck }\end{array}$ & 40.7 & [67] \\
\hline Hubei/2006 & $\begin{array}{l}\text { Satsuma mandarin/Citrus } \\
\text { unshiu Marcovitch }\end{array}$ & 26.3 & [67] \\
\hline Hubei/2006 & $\begin{array}{c}\text { Robertson navel orange/ Citrus } \\
\text { sinensis } \text { Osbeck }\end{array}$ & 20.7 & [67] \\
\hline Hubei/2005 & $\begin{array}{c}\text { Navel orange/Citrus sinensis } \\
\text { Osbeck }\end{array}$ & 78.5 & {$[38]$} \\
\hline Hubei/2005 & $\begin{array}{l}\text { Sweet orange/Citrus } \\
\text { sinensis Osbeck }\end{array}$ & 63.6 & [38] \\
\hline Hubei/2005 & $\begin{array}{l}\text { Satsuma mandarin/Citrus } \\
\text { unshiu Marcovitch }\end{array}$ & 45.8 & {$[38]$} \\
\hline Hubei/2012 & Citrus spp. & Ave. 0.56; Less than 1 & {$[103]$} \\
\hline Hubei/2006 & Citrus spp. & $40-70$ & {$[104]$} \\
\hline Hunan/1950s & Citrus spp. & $\begin{array}{l}\text { Ave. } 20-30 \\
\text { up to } 80\end{array}$ & [7] \\
\hline Hunan/2010 & $\begin{array}{l}\text { Sweet orange/ Citrus } \\
\text { sinensis Osbeck }\end{array}$ & 63 & [39] \\
\hline Hunan/2010 & $\begin{array}{l}\text { Satsuma mandarin/Citrus } \\
\text { unshiu Marcovitch }\end{array}$ & 22 (early mature varieties) & [39] \\
\hline Hunan/2010 & $\begin{array}{c}\text { Ponkan/Citrus poonensis } \\
\text { Hort. ex Tanaka }\end{array}$ & 6 & [39] \\
\hline Hunan/2010 & $\begin{array}{l}\text { Sweet orange/Citrus } \\
\text { sinensis Osbeck }\end{array}$ & 63 & [39] \\
\hline
\end{tabular}




\section{Continued}

\begin{tabular}{|c|c|c|c|}
\hline Hunan/2010 & $\begin{array}{l}\text { Wenzhou orange/Citrus } \\
\text { unshiu Marcovitch }\end{array}$ & 22 & [39] \\
\hline Hunan/2010 & $\begin{array}{c}\text { Ponkan/Citrus poonensis } \\
\text { Hort. ex Tanaka }\end{array}$ & 6 & [39] \\
\hline Hunan/2010-2012 & $\begin{array}{l}\text { Sweet orange/ Citrus } \\
\text { sinensis Osbeck }\end{array}$ & 100 & [53] \\
\hline Hunan/2010-2012 & $\begin{array}{c}\text { Satsuma mandarin/Citrus } \\
\text { unshiu Marcovitch }\end{array}$ & $55-80$ & [53] \\
\hline Hunan/2010-2012 & $\begin{array}{c}\text { Ponkan/Citrus poonensis } \\
\text { Hort. ex Tanaka }\end{array}$ & 50 & [53] \\
\hline Sichuan/1982-1992 & Citrus spp. & Avg. $20-30$ & [46] \\
\hline Sichuan/1997-2001 & Citrus spp. & $20-30$, up to $70-80$ & {$[6]$} \\
\hline Henan/1988 & $\begin{array}{l}\text { Satsuma mandarin/Citrus } \\
\text { unshiu Marcovitch }\end{array}$ & $1.2-10.5$, avg. 5.9 & [59] \\
\hline Henan/1988 & Citrus tangerina & $1.2-10.5$, avg. 5.9 & [59] \\
\hline Shaanxi/2013 & $\begin{array}{c}\text { Satsuma mandarin/Citrus } \\
\text { unshiu Marcovitch }\end{array}$ & 12 & [105] \\
\hline Shaanxi/2013 & Citrus erythrosa Tanaka & $5-7.2$ & [105] \\
\hline
\end{tabular}

Table 3. Reported hosts of B. minax in China.

\begin{tabular}{|c|c|c|}
\hline Host-Common Name/Scientific name & $\begin{array}{c}\text { Host-environment } \\
\text { (Wild/nature/cultivated) }\end{array}$ & References \\
\hline Sweet orange/Citrus sinensis Osbeck & Cultivated & $\begin{array}{c}{[2][3][32][35][36][37][38]} \\
\quad[39][67][97][106][107]\end{array}$ \\
\hline Citrus sinensis $\times$ Citrus maxima & Cultivated & [32] \\
\hline Bitter/sour orange/ Citrus aurantium L. & Cultivated & [3] [32] [35] [97] [106] \\
\hline Citrus junos & Cultivated & [32] \\
\hline Citrus tangerina & Cultivated & [2] [3] [36] [59] [97] \\
\hline Citrus limon (L.) Burm. f. & Cultivated & {$[3][36][97][106]$} \\
\hline Pomelo/ Citrus maxima (Burm) & & [2] [3] [35] [36] [97] [106] \\
\hline $\begin{array}{l}\text { Satsuma mandarin/Citrus unshiu } \\
\text { Marcovitch }\end{array}$ & Cultivated & [3] [37] [38] [67] [59] \\
\hline $\begin{array}{c}\text { Ponkan/Citrus poonensis Hort. ex } \\
\text { Tanaka }\end{array}$ & Cultivated & [39] \\
\hline Grapefruit/Pomelo/Citrus paradisi Macf & Cultivated & [38] \\
\hline $\begin{array}{c}\text { Mandarin orange/Citrus reticulata } \\
\text { Blanco cv. Tankan }\end{array}$ & Cultivated & [3] \\
\hline $\begin{array}{l}\text { Kumquat/ Fortunella margarita (Lour.) } \\
\text { Swingle }\end{array}$ & Cultivated & [3] \\
\hline Medicinal Citron/Citrus medica L. & Nature & [2] [97] [106] \\
\hline Citrusvesscosa & Nature & [32] [57] \\
\hline Poncirus trifoliata (L.) Raf. & Wild & [3] [98] \\
\hline
\end{tabular}


Table 4. B. minax fruit infestations by citrus species/cultivars.

\begin{tabular}{|c|c|c|c|c|c|c|}
\hline \multirow{2}{*}{ Citrus } & \multicolumn{6}{|c|}{ Fruit Infestation Rates (\%), based on six studies } \\
\hline & {$[39]^{*}$} & [53] & [108] & [67] & {$[35]$} & {$[32][40]$} \\
\hline Navel Orange & 63 & 100 & 100 & 40.7 & N/A & \\
\hline Ponkan & 6 & 50 & 3.0 & N/A & 0 & \\
\hline Mandarin & 18 & 55 & 74.7 & 20.7 & 0 & \\
\hline $\begin{array}{l}\text { Bingtang Orange ( } C \text {. } \\
\text { sinensis (Linn.) Osbeck } \\
\text { cv. Bing Tang) }\end{array}$ & 22 & $70-80$ & 77.2 & N/A & N/A & The papers stated \\
\hline $\begin{array}{c}\text { Dahong Orange } \\
\text { (C. sinensis } \text { (Linn.) } \\
\text { Osbeck cv. Da Hong) } \\
\text { Jinch Orange }\end{array}$ & N/A & $72-75$ & N/A & N/A & N/A & $\begin{array}{l}\text { that sweet orange } \\
\text { suffered the highest } \\
\text { fruit infestation, but } \\
\text { no data provided }\end{array}$ \\
\hline $\begin{array}{l}\text { (C. sinensis }(\text { Linn.) } \\
\text { Osbeck cv. Jincheng) }\end{array}$ & N/A & N/A & N/A & N/A & 1.7 & \\
\hline Early Ripening Satsuma & 22 & $60-68$ & 73.2 & 26.3 & N/A & \\
\hline Pomelo & N/A & N/A & 52.6 & N/A & 71.4 & \\
\hline Sour orange & N/A & N/A & 99.3 & N/A & 0.7 & \\
\hline
\end{tabular}

${ }^{*}$ reference cited.

Citrus maxima, to a Chinese sweet orange cultivar Jincheng orange judging by fruit infestation rates [35].

No study has ever been undertaken to investigate the roles of chemical and visual cues on host selection, although the color and shape of trapping devices have been studied for attracting the pest in China and Bhutan [16]. We speculate that plant phenology as well as the thickness of citrus fruit skin may play a key role in the pest's host selection. $B$. minax appears to prefer laying eggs on fruits of 2 - $4 \mathrm{~cm}$ diameter [34] [36] [37] [38] [39]. Fruit sizes of naval orange and other early ripening cultivars usually fall within this size range during the period of $B$. minax oviposition. Because of the energy cost of penetrating through the thick fruit skin, B. minax may choose to oviposit in the thin skinned fruits. This mechanism of host selection has been proved in other tephritid fruit flies [69]. Although pomelo, which have thick skins and are typically $15-25 \mathrm{~cm}$ in size, are also a preferred host of B. minax, they are attacked as young green fruits [35].

\section{Pest Management and Domestic Quarantine Measures}

Area-wide pest management or integrated pest management is not commonly adopted in China, with the exception of few large cooperative orchards in the major export citrus production counties such as Shimen in Hunan and Pinghe in Fujian. Instead, growers use one or more of the options discussed below for management of $B$. minax. There is no report of using biological control against the pest. Two studies indicated that natural enemies such as spiders and wasps had few impacts on the population of $B$. minax [3] [8]. 


\subsection{Bagging}

Fruit bagging is not a common practice in citrus groves. Exceptions can be found in those high value groves such as pomelo and lime. Few studies have ever been conducted using this approach for managing $B$. minax [25]. Rather, bagging is done for cosmetic reasons, as it gives the fruit a highly prized uniform golden color.

\subsection{Grove Sanitation and Fall/Winter Soil Treatment}

This practice is common in well-managed citrus groves. The fallen and hanging infested fruits are collected in large bags. These bags with the infested fruits are subjected to various treatments, ranging from heat treatment (by exposing the bags under the sun), boiling, deep bury, to burning [3] [6] [25] [32] [70]. Studies have indicated that good sanitation practices can significantly reduce $B$. minax infestation rates from $50 \%-100 \%$ to less than $1 \%$ [3] [25] [70].

As stated earlier, the majority of the overwintering $B$. minax pupae stay in soil at depths of $4-6 \mathrm{~cm}$. Raking and/or shallow plowing in fall/winter can expose the pupae to the cold winter temperature, and natural enemies such as birds [3] [25] [71]. Soil treatment with insecticides before adult emergence can further reduce the number of emerging population [3] [25] [70].

\subsection{Complete Removal of Food Sources of B. minax}

B. minax feeds on citrus fruits only, so theoretically, making citrus fruits unavailable during the egg-laying season can disrupt the entire population in the area. Of course, this option can be valid only under certain special circumstances such as:

1) Replanting or re-grafting citrus plants for the entire grove or area. Growers may replant the entire grove for disease management or changing to a market favorite variety [6].

2) Spraying plant growth regulators to end fruiting season before B. minax oviposition. Ethrel spraying is a common way to force citrus fruit falling prematurely [6]. This approach is valid only in the groves where B. minax occurs severely.

3) Seasonable avoidance by planting late ripening cultivars [25]. B. minax egg laying season usually falls between June and July. Certain late ripening cultivars which start fruiting in or after July should avoid the infestation.

\subsection{Control of Adult Flies by Mass-Trapping and Foliar Insecticide Application}

Mass-trapping and foliar insecticide spraying are the predominant approach to managing B. minax in China.

\subsubsection{Mass-Trapping}

Food based lures are extensively used in citrus groves in China. These lures are primarily for mass-trapping efforts only, often used together with insecticide ap- 
plication. Color sticky spheres are being used in recent years in limited groves only. Preliminary studies have been conducted to discover sex pheromones and citrus plant volatiles for attraction of $B$. minax.

Food-based lures. Food-based lures are the only type of lures used in the field. The most common food-based lures are hydrolyzed proteins, waste brewer's yeasts, and sugar + vinegar mix [37] [72] [73] [96]. Many of these lures are home and/or local-made. Field surveys and literature reviews indicated that the efficacy of these products were inconsistent, often conflicting each other. Zhou et al. [18] compared the efficacy of four lures, i.e. hydrolyzed protein (H-protein bait), a homemade bait from beer yeast, torula yeast, sugar-vinegar-wine (SVW), and Jufeng $^{\circledR}$ (a commercial protein-based fruit fly bait made in China) in 2010. The results suggested that $\mathrm{H}$-protein bait was the most effective lure, followed by SVW. Both torula yeast and Jufeng ${ }^{\circledR}$ showed poor efficacies. Our collaborators conducted a similar study using nine lures, including all four lures mentioned above, in China in 2015 and 2016. H-protein didn't show better attraction to $B$. minax than other lures (Ouyang, unpublished data). Gong et al. [74] conducted another field study using five lures, i.e. $20 \%$ hydrolyzed protein (20\% H-protein lure), Great ${ }^{\circledR} \# 1$ fruit fly lure (a common commercial protein based product in China), Jufeng ${ }^{\circledR}$ fruit fly lure, conventional sugar-vinegar-Chinese liquor (Conventional SVL), and improved sugar-vinegar-Chinese liquor (improved SVL, sugar + acetic acid + ethanol). Great \#1,20\% H-protein, Jufeng ${ }^{\circledR}$, and Improvement SVL showed no statistical difference in the attractive efficacy, although $20 \% \mathrm{H}$-protein had the highest trapping number of $B$. minax. The conventional SVL lure had the lowest trapping number, but was only statistically different from the $20 \% \mathrm{H}$-protein bait. Results from the study conducted by Zhang [37] added more inconsistencies regarding the performance of these food-based lures. Efficacy of 5\% H-protein alone was not statistically different from 5\% sugar alone (Table 5). Sugar solution or sugar vinegar mixture is a commonly used $B$. minax lure in China, usually mixed with insecticides. However, field experience and scientific studies indicated that the lure performed poorly in the field [72].

As mentioned above, Jufeng ${ }^{\circledR}$ fruit fly lure is a commonly used fruit fly lure in China. The efficacy of this product is disputable, based on grower's experience and the results from the studies cited above. However, one study claimed that 1:2 (Jufeng ${ }^{\circledR}$ lure solution: water) diluted solution of the product had the best $B$. minax attraction, compared to $2: 1$ solution, $100 \%$ Jufeng $^{\circledR}$ solution, or sugar-vinegar-Chinese liquor mixture [41]. The product label recommends using $100 \%$ Jufeng $^{\circledR}$ solution.

We conducted a two-year study comparing the performance of nine common tephritid fruit fly lures for $B$. minax attraction. The study was conducted in four groves across China's major citrus production region. The preliminary results suggested that two most common parapheromone lures-cuelure and methyl eugenol had no effect on $B$. minax, and that other food-based lures, ranging from $\mathrm{H}$-protein, and yeast, to sugar-vinegar mixture performed poorly in attracting B. minax (Xia, unpublished data). 
Table 5. Result of a field lure performance test [37].

\begin{tabular}{cc}
\hline Lure & No. of $B . \operatorname{minax}(\text { entire season })^{*}$ \\
\hline $5 \%$ H-protein & $82.7 \mathrm{~cd}$ \\
$5 \%$ Sugar & $76.0 \mathrm{~d}$ \\
$5 \%$ Sugar + 5\% Chinese liquor & $63.6 \mathrm{e}$ \\
$5 \%$ Sugar + 5\% Vinegar & $77.0 \mathrm{~d}$ \\
$5 \%$ Sugar + 5\% H-protein & $103.0 \mathrm{c}$ \\
$5 \%$ Sugar + 5\% Orange Juice & $82.3 \mathrm{~cd}$ \\
$5 \%$ Sugar + 5\% Vinegar + 5\% Chinese liquor & $90.0 \mathrm{c}$ \\
$5 \%$ Vinegar + 5\% Chinese liquor + H-protein & $179.7 \mathrm{~b}$ \\
$5 \%$ Orange + 5\% H-protein + 5\% Chinese liquor & $273.7 \mathrm{a}$ \\
$5 \%$ Sugar + 5\% Orange Juice + 5\% H-protein & $256.3 \mathrm{a}$ \\
$5 \%$ Sugar + 5\% Vinegar + 5\% Chinese liquor + 5\% H-protein & $141.3 \mathrm{bc}$ \\
\hline
\end{tabular}

* Statistical significance at $P<0.05$.

One small study tried to link trapping efficacy of lures against $B$. minax to the actual field population [72]. Twenty-one traps (7 treatment $\times 3$ rep/trt) which were deployed in 0.07 ha grove attracted roughly $1 / 20$ of the total field population. The seven treatments were 1) $3 \%$ sugar $+1 \%$ trichlorfon, 2) $3 \%$ sugar $+1 \%$ trichlorfon + Chinese liquor, 3) $10 \%$ sugar $+1 \%$ trichlorfon, 4$) 10 \%$ sugar $+1 \%$ trichlorfon + Chinese liquor, 5) $10 \%$ sugar $+1 \%$ trichlorfon + Chinese liquor, 6$)$ $20 \%$ sugar $+1 \%$ trichlorfon + Chinese liquor, 7$) 10 \%$ honey $+1 \%$ trichlorfon.

Color sticky spheres. Color sticky spheres are being increasingly used for $B$. minax pest management in recent years [16] [75] [76] [77] [78]. The earliest study of using the device for managing B. minax was actually conducted in Bhu$\tan$ by a joint team of Australia and Bhutan scientists [16]. The study found that $5 \mathrm{~cm}$-diameter-spheres were always more attractive to $B$. minax than $5 \mathrm{~cm}$-discs of the same color. Spheres of orange or green-yellow were most attractive to the fly compared with spheres of red, yellow, green, blue, black, or white. Later, a study conducted in China indicated that yellow and orange colored foods were more attractive to B. minax adults than foods in blue, green, white, red, and black [78]. Two patents on using color sticky spheres have been issued in China; one patented a $14 \mathrm{~cm}$-diameter, green-yellow sphere [75] and another patented a $7 \mathrm{~cm}$-diameter, green color sphere [77]. Xiao's patent claims that the green color sphere was more attractive to $B$. minax than orange and green-yellow colored ones. Our collaborator's recent study indicated that $7 \mathrm{~cm}$-diameter green spheres attracted the highest number of $B$. minax among nine lures, including the most popular B. minax lures in China such as hydrolyzed protein, yeast, and sugar vinegar mixture (Xia, unpublished data).

Sex pheromone and citrus plant chemicals. Preliminary work has been carried out in China to discover a female sex pheromone and plant volatiles that might 
improve lure efficacy. This work is summarized in Table 6. Laboratory studies indicated that $B$. minax males responded to gland and/or rectum extracts of females, and to a lesser extent of the same sex. Two field studies showed inconsistent outcomes. Xiao et al. [79] demonstrated the female rectum extract had the highest attraction to both males and females, compared to three other lures (Table 7). However, the field study conducted by Xia \& Hong [80] failed to demonstrate the female rectum extract attracted males, in spite of the positive response in a lab study. The scientists claimed that 2,6-di-tert-butyl-p-cresol (BHT) is the sex pheromone. A patent claiming undecanol as the female sex pheromone of $B$. minax has been granted to another institute [81]. We are not aware of any field efficacy data available for the patented compound.

Since B. minax is an oligophagous insect, feeding on the fruits of Rutaceae plants only, citrus plant volatiles may play a critical role in B. minax host finding and oviposition behavior. A recently published laboratory study revealed that female adults were attracted to nonanal, citral, limonene and linalool from citrus fruits (Table 6).

\subsubsection{Foliar Pesticide Spray}

Foliar spraying of insecticide during the early adult stage around late April to May is one of the most common B. minax management options in China. Commonly used insecticides are organophosphates such as trichlorfon and/or pyrethroids such as deltamethrin. These insecticides are usually applied weekly using backpack or small mechanical sprayers. Unfortunately, in spite of the numerous publications on the topic [25] [73] [82] [83], few of these publications provided solid scientific data on the efficacy of the sprays. Xu [84] compared the efficacy of foliar sprays of fipronil, trichlorfon, and water, found 3.2, 11.0, and $21.3 \%$ B. minax-caused fallen fruits at harvest, respectively (Table 8). However,

Table 6. Studies on B. minax pheromone \& plant volatiles in China.

\begin{tabular}{|c|c|c|c|c|c|}
\hline \multirow{2}{*}{ Odor source } & \multicolumn{2}{|r|}{ Lab Bioassay } & \multicolumn{2}{|r|}{ Field Evaluation } & \multirow{2}{*}{ Ref. } \\
\hline & method & response & method & response & \\
\hline Rectum extract $^{1}$ & Wind tunnel & $\begin{array}{l}\text { Males responded to female's } \\
\text { extracts, not vice versa }\end{array}$ & Field cage & $\begin{array}{l}\text { B. minax flied surrounding the } \\
\text { cage, but none inside }\end{array}$ & [80] \\
\hline $\begin{array}{l}\text { Filter paper treated with } \\
\text { Female rectum extract }\end{array}$ & $\begin{array}{l}\text { EAG \& } 500 \mathrm{ml} \\
\text { Bottle }\end{array}$ & $\begin{array}{l}\text { Males responded to female's } \\
\text { extract }\end{array}$ & N/A & N/A & [109] \\
\hline $\begin{array}{l}\text { Rectum extract }(4,10 \text {, } \\
15 \text {-day-old adults of both sex }\end{array}$ & EAG & $\begin{array}{l}\text { Both males and females } \\
\text { responded highly to the } \\
\text { 15-day-old fly's extracts of } \\
\text { rectum extracts of the opposite } \\
\text { sex and the same sex }\end{array}$ & Field trap & $\begin{array}{c}\text { 15-day-old females rectum extracts } \\
\text { had the high attraction to both } \\
\text { males and females (see Table } 8 \\
\text { below) }\end{array}$ & [79] \\
\hline $\begin{array}{l}\text { Rectum extracts of mating } \\
\text { females and males }{ }^{2}\end{array}$ & Y tube & $\begin{array}{l}\text { Males shows strong reaction to } \\
\text { extracts of females }\end{array}$ & N/A & N/A & [81] \\
\hline $\begin{array}{l}\text { Plant volatiles/oils of } \\
\text { citrus fruits }\end{array}$ & Y tube & $\begin{array}{l}\text { Females are attracted to nonanal, } \\
\text { citral, limonene and linalool }\end{array}$ & N/A & N/A & [24] \\
\hline
\end{tabular}

${ }^{1}$ 2,6-di-tert-butyl-p-cresol (BHT); ${ }^{2}$ Undecanol. 
Table 7. Attractive efficacy of rectum extracts of B. minax vs. other food-based lures [79].

\begin{tabular}{ccc}
\hline Lure or extracts & Average trapping number & Sex ratio (female/male) \\
\hline Female rectum extracts & $40.67 \pm 2.21 \mathrm{a}$ & $0.82: 1$ \\
Male rectum extracts & $5.33 \pm 0.80 \mathrm{c}$ & $2.56: 1$ \\
Hydrolyzed protein & $24.25 \pm 1.96 \mathrm{~b}$ & $4.71: 1$ \\
Sugar solution with wine vinegar mixture & $1.00 \pm 0.17 \mathrm{c}$ & $3.00: 1$ \\
Control (n-Hexane) & $0 \mathrm{c}$ & - \\
\hline
\end{tabular}

*Statistical significance at $P<0.05$.

Table 8. Efficacy of foliar insecticide spraying [84].

\begin{tabular}{ccccc}
\hline & & & \% fallen fruit due to $B$. minax & \\
\hline SiteTrt & I & II & III & Ave \\
Trichlorfon & 11.0 & 9.0 & 13.0 & 3.2 \\
Fipronil & 4.0 & 2.5 & 3.2 & 21.3 \\
Water & 19.0 & 24.0 & 21.3 & 3.0 \\
\hline
\end{tabular}

there was no explanation on the differences such as $B$. minax population among the three test sites, or statistical analysis of the results.

Sterile insect technique (SIT). Using SIT for managing B. minax was once a national priority project in the late 1980s to the early 1990s. Several sterile insect release studies have been carried out in Guizhou province. These studies were primarily conducted by a team of scientists from the Institute of Nuclear Applications, China Academy of Agricultural Sciences \& the Institute of Nuclear Applications, Zhejiang Academy of Agricultural Sciences [1]. A total of 56,272 and 95,320 sterile male adults, which were treated with cobalt-60 at a dose of $90 \mathrm{~Gy}$ at pupal stage, were released into a 31 ha, 10-year Satsuma mandarin (C. unshiu) grove, in 1987 and 1989, respectively. The ratio of released to wild flies was 12.5:1 and 45:1, respectively, in the two releases. The first release (1987) resulted in a reduction of fruit infestation rate from $7.5 \%$ in 1986 to $0.20 \%$ in 1987; the second release (1989) further reduced the infestation rate from $0.16 \%$ in 1988 to $0.005 \%$ in 1989 . The group conducted even larger releases in Guizhou province in 1993 and 1994. A total of 593,000 and 1,000,200 of sterile male adults were released into seven 120-ha, 10-plus-year-old Satsuma mandarin groves. The irradiation treatment was the same as the studies conducted in 1987 and 1989. The release in 1993 resulted in a reduction of the fruit infestation rate from $5.2 \%$ (the average fruit infestation rate in previous three years) to $0.134 \%$, which was further reduced to $0.098 \%$ following the second release in 1994 . All released flies in the studies were from natural populations, i.e. the infested fruits were collected at the late larval stage. These fruits were then placed in containers with sand to allow the larvae to pupate. The pupae were then collected by hand, and treated with the aforementioned irradiation dose. 
Technical obstacles were the major challenge [85]. B. minax is a univoltine species, it has proved very challenging to mass-rear and field collections are very expensive.

\subsection{Domestic Quarantine and Inspection}

As discussed above, B. minax is not on the list of domestic quarantine pests in China [65]. Therefore, there are no inspections or restrictions against the movement of this species in China.

\section{Phytosanitary Treatment}

So far, study of phytosanitary measures of $B$. minax has focused primarily on two approaches: irradiation and cold treatment.

\subsection{Irradiation}

The impacts of irradiation on B. minax larvae inside of citrus fruits (a mix of pomelo and sweet orange) have been studied. Zhao et al. [86] used cobalt-60 to treat 3rd instars. The mortality of treated larvae rose as the treatment dose increased from $10 \mathrm{GY}$ to $1 \mathrm{KGy}$. The surviving larvae from the treatment pupated $100 \%$, but fewer adults emerged from the higher dose treatment. When the treatment dose reached $50 \mathrm{GY}$, no adults emerged. LD50 and LD100 of larvae and pupae were 2.76 and $87.78 \mathrm{KGy}$, and 20.4 and $70 \mathrm{GY}$, respectively. Gao et al. [87] conducted similar studies in 1994, 1995, and 1996, suggesting 90 Gy is needed to reach zero adult emergence from treated pupae.

\subsection{Cold Treatment}

Although we don't know precisely how $B$. minax reacts to cold treatment, there is strong evidence that this pest should be amongst the coldest tolerant Bactrocera species. First, as discussed earlier, the distribution of this species is primarily in the temperate area of south central China; second, several small-scale studies indicate that $B$. minax can survive freezing temperatures for days. Fan et al. [31] studied the impact of temperature on the survival of 3rd instar larvae. Twenty larvae were placed between two moisture tissues inside a beaker (each beaker was a replicate, with three replicates per treatment). A total of five treatments, i.e. three temperature treatments: $0^{\circ} \mathrm{C}, 3^{\circ} \mathrm{C}, 6^{\circ} \mathrm{C}$, and two control treatments: $21^{\circ} \mathrm{C}$ and natural room temperature, were included in the study. Under $0^{\circ} \mathrm{C}$ treatment, first larval death occurred on day 12 , and larval mortality reached $55 \%$ on day 22 , and $93 \%$ on day 23 . Whereas under a natural room temperature of $11.5^{\circ} \mathrm{C}$, larval mortality occurred on day 20 , and only reached $6 \%$ mortality by day 29 . There was no mortality under $21^{\circ} \mathrm{C}$ control treatment during the observation period. However, another similar study using 2 nd instars showed quite a different outcome [90]. After treatment with $0^{\circ} \mathrm{C}$ for $1 \mathrm{~h}$, the treated larvae were moved to an environmental chamber under $25^{\circ} \mathrm{C} \pm 1^{\circ} \mathrm{C}$, where $80 \%$ larval death was recorded within $24 \mathrm{~h}$. In another study conducted by Huang et al. [88], the 
supercooling and freezing points of $B$. minax were evaluated. The 3rd instar larvae have a supercooling point and freezing point of -7.09 and $-3.43^{\circ} \mathrm{C}$, respectively. A low supercooling point indicates a high resistance to cold [89].

In summary, irradiation treatment appears to be a more promising $B$. minax phytosanitary treatment, compared to the prospect of cold treatment.

\subsection{Heat Treatment}

Few studies were conducted using heat treatment as an option of B. minax phytosanitary treatment. Liu et al. [90] showed that 3rd instars died 100\% following 1h of exposure to $47^{\circ} \mathrm{C}$. Unfortunately, the methodology used to perform their experiments is not clearly explained. Since $B$. minax is tolerant to cold temperature, it is not a surprise that this species might be susceptible to high temperature.

\section{Scientific and Technological Gaps in Safeguarding Citrus Industry from $B$. minax Invasion}

The risk of introducing $B$. minax into other major citrus production regions of the world rises significantly as China expands its fresh citrus market globally, as well as the exponentially increasing number of travelers from and into China. International collaboration is essential to minimize the risk, and smooth the fresh citrus trade and human traffic. Based on the review above, we identified some critical scientific and technological gaps in preventing the invasion of this destructive pest. These gaps include:

\subsection{Inadequate Work on Phytosanitary Measures}

Although a number of phytosanitary treatment studies of $B$. minax had been conducted in China, these studies were preliminary and small-scale. Among the measures studied, irradiation shows great promise. International collaborative work between China and the potential import countries is critical to validate the efficacy of the treatment, as well as the potential impact on fruit quality. Significant progress has been made in recent years in understanding the efficacy of irradiation against tephritid fruit flies inside fresh fruits, as well as the impact of irradiation on fruit quality [91].

There are not sufficient data to make a decision regarding a cold treatment schedule suitable for B. minax phytosanitary treatment. As discussed earlier, this species might be among the most cold-tolerant Bactrocera fruit fly.

Heat treatment remains an option. Schedule T106-a-4 $\left(43.3^{\circ} \mathrm{C}\right.$ for $\left.6 \mathrm{~h}\right)$ results in 100\% mortality for Anastrapha species [92]. However, it is not known if the schedule is effective enough for $B$. minax. Studies have to be carried out assessing the efficacy as well as impact on fruit quality.

\subsection{Lack of Effective Lure for Early Detection and Emergency Response}

The US citrus industry has faced a series of severe pest invasions in recent years, 
and the invasion of $B$. minax would have a devastating impact on the industry. An effective lure is the first necessary tool once an invasion fruit fly occurs. Many of the successful eradications of invasive Bactrocera in the US can be credited to having potent lures which can detect the invasive pest at very low population levels. In the case of $B$. minax, the role of an effective lure can be more significant in the early response and eradication program, compared to the invasions of other tephritid fruit flies such as B. dorsalis or Ceratitis capitata. SIT can be deployed for eradication of $B$. dorsalis or $C$. capitata. However, there is no case of using SIT for the univoltine, oligophagous tephritid fruit flies such as $B$. minax, primarily due to the challenge in mass rearing these pests.

This review reveals that there is no effective lure for early detection and emergency response. Unless more potent lures are available, the risk of the pest's ability to spread and establish the US, as well as in world's other major citrus regions, is substantial.

\subsection{Weak Delimiting and Understanding B. Minax Pest Free Area in China}

Since there is no internationally recognized phytosanitary treatment available for B. minax, delimiting B. minax pest free areas can play a critical role in promoting safe trade and safeguarding. B. minax is not reported in four southern citrus provinces in China. However, it is premature to say that these provinces are $B$. minax pest free areas. Determining $B$. minax pest free areas can be especially challenging. Trapping for this species is not very effective, so fruit sampling might be necessary to ensure the quality of the survey work. We are not aware that any effort has ever taken in determining $B$. minax pest free areas in China. This work has to follow an internationally recognized approach such as ISPM No 26 [93].

\section{Acknowledgements}

Authors wish to thank Drs. Ken Bloem, Karl Suiter, Roger Magarey, Yu Takeuchi, and Ms. Sarah Marnell for technical assistance and/or review this writing. This work is partially funded by USDA-Animal and Plant Health Inspection Service-Plant Protection and Quarantine-Science \& Technology.

\section{References}

[1] Wang, H.S., Zhao, C.D., Li, H.Y., Lou, H.Z., Liu, Q.R., Kang, W., Hu, J.G., Zhang, H.Q., Chu, J.M., Xia, D.R. and Yang, R.X. (1990) Effect of Irradiation Sterile to Control Bactrocera minax. Acta Agriculture Nucleatae Sinica, 4, 135-138. [In Chinese]

[2] Ni, D.Y., Liu, Q.X. and Guo, S.H. (1990) Observation and Control of Bactrocera minax. Hubei Forestry Science Technology, 73, 39-41. [In Chinese]

[3] Wang, X.J. and Luo, Y.L. (1995) Advanced Study on Bactrocera minax. Chinese Bulletin of Entomology, 32, 310-315. [In Chinese]

[4] Lu, H.X., He, K.P., Ruan, H.F. and Mu, B.Z. (1997) The Biological Features of Chi- 
nese Citrus Fly Dacus citri (Chen). Journal of Hubei Agricultural College, 17, 169-173. [In Chinese]

[5] Lu, H.X. and Liu, M.X. (1999) Pattern of Occurrence of Bactrocera minax in Sanxia Region. Acta Agriculture Nucleatae Sinica, 19, 310-312. [In Chinese]

[6] Fan, J.A. (2002) Occurrence and Control of Bactrocera minax in Sichuan. Plant Quarantine, 16, 150-152. [In Chinese]

[7] Sun, T.A. (2004) Preliminary Report of Occurrence and Control of Bactrocera minax. Plant Quarantine, 18, 108-109. [In Chinese]

[8] Huang, D.S., Xiao, G.Z., Yang, Z.A. and Wen, J.Z. (2007) The Damage and Control Technology of Bactrocera (Tetradacus) minax Enderlein in Taoyuan County. Plant Quarantine, 4, 233-235. [In Chinese]

[9] ANUFOOD China (2015) Export Market Analysis for Chinese Citrus. http://www.anufoodchina.com/Item/Show.asp?m=1\&d=2764

[10] SAGARPA and AQSIQ (2014) Protocol of Phytosanitary Requirements for the Exporting of Citrus from China to Mexico, Between the Secretary of Agriculture, Livestock, Rural Development, Fisheries and Food of the United Mexican States and the General Administration of Quality Supervision, Inspection and Quarantine of the People's Republic of China.

https://www.gob.mx/cms/uploads/attachment/file/165719/Protocolodeimportaci_n dec_tricosdeChina.pdf

[11] APHIS (2014) Proposed Rules: Importation of Fresh Citrus from China into the Continental United States.

https://www.regulations.gov/document?D=APHIS-2014-0005-000

[12] APHIS (2014) Initial Regulatory Flexibility Analysis: Importation of Fresh Citrus from China into the Continental United States.

https://www.regulations.gov/document?D=APHIS-2014-0005-0002

[13] APHIS (2014) Importation of Citrus spp. from China into the Continental United States, a Qualitative, Pathway-Initiated Pest Risk Assessment. https://www.regulations.gov/document?D=APHIS-2014-0005-0003

[14] APHIS (2014) Risk Management Document, Importation of Fresh Citrus (Citrus grandis cv. Guanximiyou, Citrus kinokuni, Citrus poonensis, Citrus sinensis and Citrus unshiu) Fruit from China into the Continental United States. https://www.regulations.gov/document?D=APHIS-2014-0005-0004

[15] Zhang, Y.A. (1989) Citrus Fruit Flies of Sichuan Province (China). OEPP/EPPO Bulletin, 19, 649-654. https://doi.org/10.1111/j.1365-2338.1989.tb01154.x

[16] Drew, R.A., Dorji, C., Romig, M.C. and Loday, P. (2006) Attractiveness of Various Combinations of Colors and Shapes to Females and Males of Bactrocera minax (Diptera: Tephritidae) in a Commercial Mandarin Grove in Bhutan. Journal of Economic Entomology, 99, 1651-1656. https://doi.org/10.1093/jee/99.5.1651

[17] Gui, L.Y., Huang, X.Q., Li, C.R. and Boiteau, G. (2011) Validation of Harmonic Radar Tags to Study Movement Of Chinese Citrus Fly. The Canadian Entomologist, 143, 415-422. https://doi.org/10.4039/n11-017

[18] Zhou, X.W., Niu, C.Y., Han, P. and Desneux, N. (2012) Field Evaluation of Attractive Lures for the Fruit Fly Bactrocera minax (Diptera: Tephritidae) and Their Potential Use in Spot Sprays in Hubei Province (China). Journal of Economic Entomology, 105, 1277-1284. https://doi.org/10.1603/EC12020

[19] Dong, Y.C., Wang, Z.J., Clarke, A.R., Pereira, R., Desneux, N. and Niu, C.Y. (2013) Pupal Diapause Development and Termination Is Driven by Low Temperature 
Chilling in Bactrocera minax. Journal of Pest Science, 86, 429-436.

https://doi.org/10.1007/s10340-013-0493-y

[20] Dong, Y.C., Desneux, N., Lei, C.L. and Niu, C.Y. (2014) Transcriptome Characterization Analysis of Bactrocera minax and New Insights into Its Pupal Diapause Development with Gene Expression Analysis. International Journal of Biological Sciences, 10, 1051-1063. https://doi.org/10.7150/ijbs.9438

[21] Dong, Y.C., Wan, L., Pereira, R., Desneux, N. and Niu, C.Y. (2014) Feeding and mating Behavior of Chinese Citrus Fly Bactrocera minax (Diptera, Tephritidae) in the Field. Journal of Pest Science, 87, 647-657.

https://doi.org/10.1007/s10340-014-0605-3

[22] Zhang, B., Nardi, F., Hull-Sanders, H., Wan, X.W. and Liu, Y.H. (2014) The Complete Nucleotide Sequence of the Mitochondrial Genome of Bactrocera minax (Diptera: Tephritidae). PLOS ONE, 9, e100558. https://doi.org/10.1371/journal.pone.0100558

[23] Chen, Z., Dong, Y., Wang, Y., Andongma, A.A., Rashid, M.A, Krutmuang, P. and Niu, C. (2016) Pupal Diapause Termination in Bactrocera minax. An Insight on 20-Hydroxyecdysone Induced Phenotypic and Genotypic Expressions. Scientific Reports, 6, 1-10. https://doi.org/10.1038/srep27440

[24] Liu, L. and Zhou, Q. (2016) Olfactory Response of Female to Chemical Components of the Preference Host Citrus Volatile Oils. Journal of Asia-Pacific Entomology, 19, 637-642. https://doi.org/10.1016/j.aspen.2016.05.008

[25] Wang, X.L. and Zhang, R.J. (2009) Review on Biology Ecology and Control of Bactrocera minax Enderlein. Journal of Environmental Entomology, 31, 73-79. [In Chinese]

[26] Yang, W.S., Li, C.R., Lan, J. and An, H.L. (2013) The Spread Mode and Dispersal History of Chinese Citrus Fly by Literature Research. Journal of Yangtze University (Natural Science Edition), 10, 8-11. [In Chinese]

[27] Zhang, G.F., Wang, F.L., Lv, Z.C., Hong, C., Li, Y.J., Guo, J.Y., Li, C.R. and Wan, F.H. (2015) Research Progress on the Biology, Ecology and the Application of Sterile Insect Technique on Bactrocera minax (Enderlein). Journal of Biosafety, 24, 171-176. [In Chinese]

[28] Dorji, C., Clarke, A.R., Drew, R.A.I., Fletcher, B.S., Loday, P., Mahat, K., Raghu, S. and Romig, M.C. (2006) Seasonal Phenology of Bactrocera minax (Diptera: Tephritidae) in Western Bhutan. Bulletin of Entomological Research, 96, 531-538.

[29] Chen, S.X. and Xie, Y.Z. (1955) Taxonomic Notes on the Chinese Citrus Fly Tetradacus citri Chen. Acta Entomologica Sinica, 5, 123-126. [In Chinese]

[30] Luo, Y.L. and Chen, C.F. (1987) Pupal Biological Characteristics of Tetradacus citri Chen. China Citrus, 4, 9-10. [In Chinese]

[31] Fan, J.A., Zhao, X.Q. and Zhu, J. (1994) A Study of the Cold-Resistance and Diapause in Tetradacus citri Chen. Journal of Southwest Agricultural University, 16, 532-534. [In Chinese]

[32] Chen, Z.M. (1957) Preliminary Report of Observation on the Living Habits and Control Experiments of Tetradacus citri Chen. Huazhong Agricultural Sciences, 4, 280-282. [In Chinese]

[33] Wu, Z.Q. (1958) Preliminary Report of Observation on the Living Habits of Tetradacus citri Chen. Chinese Bulletin of Entomology, 5, 216-217. [In Chinese]

[34] Wu, Z.Q. (1973) A Brief Introduction to Tetradacus citri Chen. Southwest Horticulture, 1, 34-35. [In Chinese] 
[35] Yang, S.G. (1989) Occurrence and Control of Chinese Citrus Fly in Yanhe, Guizhou. Journal of Guizhou Agricultural Science, 6, 23-26. [In Chinese]

[36] Zhang, Y.A. (1985) Identification of Damage Symptoms of Citrus Bactrocera minax. China Citrus, 3, 23-24. [In Chinese]

[37] Zhang, X.Y. (2007) Studies on Biology, Behavior and Control of Bactrocera minax. M.S. Thesis, Huazhong Agricultural University, Wuhan, Hubei. [In Chinese]

[38] Zhang, X.Y., Yu, F.J., Han, Q.H., Zhou, X.M. and Lei, C.L. (2007) Preference and Performance of Bactrocera (Tetradacus) minax on Three Host Plants. Chinese Bulletin of Entomology, 44, 364-366. [In Chinese]

[39] Lin, W.L., Yang, S.Z., Pan, M.S., Chen, H.L., Huang, Z.P., Long, J.G. and Xiao, F.L. (2011) The Damage Characteristics of Tetradacus citri Chen on Different Citrus Varieties in Hunan Province. Hunan Agricultural Sciences, 23, 95-97. [In Chinese]

[40] Deng, M.L. (1985) Occurrence and Control of Bactrocera minax in Jiangjin County. Plant Quarantine, 4, 40-41. [In Chinese]

[41] Lei, B.H., Zhong, J.M. and Pan, W.T. (2009) Preliminary Report on Monitoring of Fruit Flies Infecting Fruits and Vegetables in Kaili Area. Southwest China Journal of Agricultural Sciences, 22, 963-965. [In Chinese]

[42] Zheng, B.G., Wang, Z., Liao, Q.R. and Yang, H. (2013) Investigation in the Occurrence of Bactrocera minax in Qinglong County. Journal of Mountain Agriculture and Biology, 32, 411-414. [In Chinese]

[43] Wang, T., Ren, Y.L., Yang, M.F. and Zhang, R.Z. (2015) Diversity Characteristics of Fruit Flies in Xingyi, Guizhou, Southwestern China. Acta Entomologica Sinica, 58, 569-578. [In Chinese]

[44] Fan, J.A., He, T.J., He, W.X., Long, W.D., Zhu. J. and Hu, X.Q. (2003) Fruit Fly Monitoring in Sichuan. Plant Quarantine, 17, 281-282. [In Chinese]

[45] Fan, J.A., He, T.J., He, W.X., Long, W.D., Zhu, J. and Hu, X.Q. (2003) Studies on the Occurrence and Geographical Distribution of Fruit Flies Infecting Fruits and Vegetables Inspected with Lure in Sichuan. Southwest China Journal of Agricultural Sciences, 16, 70-73. [In Chinese]

[46] Zhao, X.Q., Fan, J.A. and Qin, Z. (1993) A Survey of Fruit Flies on Vegetable and Fruits in Sichuan Province. Journal of Southwest Agricultural University, 15, 329-332. [In Chinese]

[47] Chen, F.J. and Wang, F.P. (1943) The Maggots in Jiangjin County. Scientific Agriculture, 1, 46-59. [In Chinese]

[48] Lei, H.D., Hu, J.H., Li, H.J., Liu, H.Q. and Yao, T.S. (2005) Advances on the Study of Dangerous Citrus Pests. Disaster Prevention and Control of Biological Agriculture. Proceedings of Ninth National Congress of Crop Protection, Beijing, 1 October 2015, 510-515. [In Chinese]

[49] Tang, S., Zhao, Z.M., Wang, J.J., Yang, Z.W., Tian, J., Liu, X.M., Fan, K.J., Yuan, W.B. and Fei, Q. (2014) Study on Systematic Monitor of Bactrocera minax Occurrence in Chongqing. Journal of Environmental Entomology, 36, 44-50. [In Chinese]

[50] Lv, Z.Z. (2006) Observation of Eclosion, Mating and Oviposition Habits of Bactrocera minax in Yichang Area. Plant Quarantine, 20, 215-216. [In Chinese]

[51] Wang, Z.J., Jiang, Y.C., He, L.G., Wu, L.M., Tong, Z. and Xu, M. (2011) Fruit Fly Survey and Comparison of Adults' Characteristics in Citrus Orchard in Wuhan. Hubei Plant Protection, 6, 19-20. [In Chinese]

[52] JBT Corporation (2011) Citrus Production and Utilization in China. https://conference.ifas.ufl.edu/citrus09/Presentations/Wednesday/1120\%20Cheng\% 
20for\%20print.pdf

[53] Lin, W.L., Xiao, F.L. and Yang, S.Z. (2013) A Preliminary Study on Chinese Citrus Fly in Hunan Province. Hunan Agricultural Sciences, 15, 84-86. [In Chinese]

[54] Deng, Y.P. and Qiu, Q. (2008) Survey of Fruit Flies Occurrence in Guangxi. Guangxi Horticulture, 19, 22-24. [In Chinese]

[55] Liu, G., Gao, X., Zhang, Y., Wang, Q. W., Zhang, J.C., Zhang, K., Li, L. and Huang, B.Q. (2014) Occurrence and Control of Bactrocera minax in Hanzhong. Journal of Shaanxi, Agricultural Sciences, 60, 112-113. [In Chinese]

[56] Zhao, X.X., Cui, M. and Yin, Z.X. (2007) Occurrence and Control of Bactrocera minax in South of Shaanxi Province. Journal of Shaanxi Agricultural Sciences, 1, 181. [In Chinese]

[57] Duan, Y.P. (1989) Dacus (Zeugodacus) Scutellatus Hendel Was Found in Shaanxi. Plant Protection, 15, 38. [In Chinese]

[58] Li, B.L. (2014) Survey on the Fruit Fly Species in the Export Fruit Base in Shaanxi Province. Master's Thesis, Northwest A \& F University, Yangling. [In Chinese]

[59] Li, X.F. and Yang, G.F. (1991) Bactrocera minax Was Found in Xichuan, Henan Province. China Citrus, 20, 41. [In Chinese]

[60] Ma, J., Lin, J.T., Chen, H.J. and Hu, X.N. (2009) The Potential Role of Interspecific Competition in Fruit Fly Invasion. Journal of Environmental Entomology, 31, 361-364. [In Chinese]

[61] Duyck, P.F., David, P. and Quilici, S. (2004) A Review of Relationships between Interspecific Competition and Invasions in Fruit Flies (Diptera: Tephritidae). Ecological Entomology, 29, 511-520. https://doi.org/10.1111/j.0307-6946.2004.00638.x

[62] Frederick Jr., G.G. and Hu, X.L. (1990) The Possible Role of Yunnan, China, in the Origin of Contemporary Citrus Species (Rutaceae). Economic Botany, 44, 267-277. https://doi.org/10.1007/BF02860491

[63] Xie, S.P., Manchester, S.R., Liu, K.N., Wang, Y.F. and Sun, B.N. (2013) Citrus linczangensis sp. n., a Leaf Fossil of Rutaceae from the Late Miocene of Yunnan, China. International Journal of Plant Science, 174, 1201-1207. https://doi.org/10.1086/671796

[64] Sheng, C. (2009) Review of China's Citrus Production of Last 60 Years. Fruit Farmers, 10, 3-12. [In Chinese]

[65] Ministry of Agriculture (MOA) of the People's Republic of China (PRC) (2009) Announcement No. 1216: National List of Agricultural Phytosanitary Pests. http://www.moa.gov.cn/ztzl/gjzwbhgy/tjxx/201205/t20120506_2617762.htm

[66] Xia, Z.M. (1998) Kinds of Plant's Quarantine Object and Their Damage in Guizhou. Guizhou Agricultural Sciences, 26, 21-23. [In Chinese]

[67] Zhang, X.Y., Zhou, X.M., Huang, S.Z., Han, Q.H. and Lei, C.L. (2007) The Oviposition Preference of Bactrocera (Tetradacus) minax. Chinese Bulletin of Entomology, 44, 867-870. [In Chinese]

[68] Yang, Y.Z., Zhang, F.G. and He, T. (2008) Occurrence, Damage and Control of Bactrocera minax. Hubei Plant Protection, 1, 18. [In Chinese]

[69] Atallah, J., Teixeira, L., Salazar, R., Zaragoza, G. and Kopp, A. (2014) The Making of a Pest: The Evolution of a Fruit-Penetrating Oviposition Drosophila suzukii and Related Species. Proceedings of the Royal Society B: Biological Sciences, 281, 20132840. https://doi.org/10.1098/rspb.2013.2840

[70] Peng, W.M. (1990) A Brief History of the Occurrence and Control of Bactrocera minax in Jiangjin County. China Citrus, 19, 31-36. [In Chinese] 
[71] Guo, E.P., Lu, X.Z., Ouyang, Y.F. and Yan, X.F. (2008) Biological Characteristics and Integrated Control Strategies of Bactrocera minax. South China Fruits, 37, 20-21. [In Chinese]

[72] Tian, M.H., Guo, S.Z., Lv, Z.Z. and Li, H.L. (2005) Attraction Effects of Different Lures on Bactrocera minax. Hubei Plant Protection, 6, 27-28. [In Chinese]

[73] Shu, X.L. and Xiao, Z.J. (2006) The Occurrence and Control of Bactrocera (Tetradacus) minax Enderlein. Plant Doctor, 19, 26. [In Chinese]

[74] Gong, Q.T., Zhao, Z.M., Sun, R.H., He, L., Xiao, W. and Li, S.H. (2014) Electrophysiological Activity of Some Materials to Chinese Citrus Fly and Their Attraction in Field. Journal of Environmental Entomology, 36, 95-101. [In Chinese]

[75] Niu, C.Y., Zhou, X.W., Han, P., Dong, Y.C. and Ye, Z.P. (2011) A Type of Trap for Bactrocera minax. China, Patent, CN201854616U. [In Chinese]

http://www.pss-system.gov.cn/sipopublicsearch/patentsearch/searchHomeIndex-se archHomeIndex.shtml?params=4C3F74C3281B65A97F2870FF32DEFA09A83706D D04F50CE9502A31B335B4A93ED57C42416D5A10992A5B056A5D573E7A5C872B 71B061545EA82FA94C4763A52F193D5708C9A494B19A7471FA7721AF4F

[76] Yi, J.P., Li, S.H., Zhang, G.G., Xiang, F., Zhou, G.Z. and Luo, H.G. (2015) Application of Green-Yellow Sphere Trap to Trapping Bactrocera minax. China Plant Protection, 35, 34-37. [In Chinese]

[77] Xiao, F.L., Yang, S.F., Gong, B.Y., Li, X.X., Lin, W.L., Zhou, C.F. and Liao, W. (2016) A Type of Trap for Bactrocera minax Adults. China, Patent CN205455518U. [In Chinese]

http://www.pss-system.gov.cn/sipopublicsearch/patentsearch/searchHomeIndex-se archHomeIndex.shtml?params=4C3F74C3281B65A97F2870FF32DEFA097A78206 AFC2D67F0B0A5E5359217662DD57C42416D5A10992A5B056A5D573E7A5C872B 71B061545EA82FA94C4763A52F193D5708C9A494B19A7471FA7721AF4F

[78] You, K.X., Si, P.F., Zhou, Q. and Liu, L. (2016) Tendency and Olfactory Response of Drosophila melanogaster to Different Colors and Carbohydrates. Central China Insect Research, 12, 356. [In Chinese]

[79] Xiao, W., Wu, K.M., Gong, Q.T., Zhao, Z.M. and He, L. (2013) Pheromonal Activity of Rectum Extracts from Chinese Citrus Fly (Bactrocera minax). Scientia Agricultura Sinica, 46, 1501-1508. [In Chinese]

[80] Xia, Z.Y. and Hong, Z.S. (1997) A Preliminary Study on Sex Pheromone of Bactrocera minax. Journal of Chinese Medical Materials, 20, 492-493. [In Chinese]

[81] Zhou, Q., Liu, L., You, K.X. and Jing, Q. (2015) The Extracting Method and Application of a Sex Pheromone of Bactrocera minax. China, Patent CN103766336B. [In Chinese]

http://www.pss-system.gov.cn/sipopublicsearch/patentsearch/searchHomeIndex-se archHomeIndex.shtml?params=4C3F74C3281B65A97F2870FF32DEFA09E886388 95325CB4E225721055D67AFF1D57C42416D5A10992A5B056A5D573E7A5C872B7 1B061545EA82FA94C4763A52F193D5708C9A494B19A7471FA7721AF4F

[82] Wu, S.H., Zhang, Z.L. and Liang, D.G. (2008) Discussion on the Causes and Control Measures on Bactrocera minax in Huitong County. South China Fruits, 37, 24-26. [In Chinese]

[83] National Agriculture Technology Extension and Service Center (NATESC) (2016) Prevention and Control Technology Scheme of Bactrocera (Tetradacus) minax. Plant Protection, 10, 113. [In Chinese]

[84] Xu, J. (2007) Field Study of a Fipronil Bait for Control of Bactrocera minax. Hubei Plant Protection, 2, 34. [In Chinese] 
[85] Dong, Y.C., Niu, C.Y., Han, P., Chen, Z., Lei, C.L. and Pereira, R.C. (2010) Preliminary Study in Artificial Rearing of Chinese Citrus Fruit Fly, Bactrocera minax (Enderlein).

https://www-pub.iaea.org/mtcd/meetings/PDFplus/2010/38586/Presentations/AMR QC12_0058.pdf

[86] Zhao, X.Q., Fan, J.A., Xie, C.L., Qin, Z., Li, G., Zhu, J., Zeng, D.B. and Kong, F.C. (1995) Gamma Irradiation as a Quarantine Treatment against Tetradacus citri in Pomelo and Orange Fruits. Journal of Southwest Agricultural University, 17, 126-129. [In Chinese]

[87] Gao, M.X., Wang, C., Li, S.R. and Tang, Z.X. (1999) The Study of Irradiation on Pest in Orange and Chestnut. Plant Quarantine, 13, 197-199. [In Chinese]

[88] Huang, C., Li, Z.Y., Wang, F.L., Zhang, G.F., Li, C.R. and Li, Y.J. (2014) The Supercooling Point and Freezing Point of Mature Larva and Pupa of Bactrocera minax (Enderlein). Journal of Environmental Entomology, 36, 17-21. [In Chinese]

[89] Lee, R.E. (1991) Principles of Insect Low Temperature Tolerance. In: Lee, R.E. and Denlinger, D.L., Eds., Insects at Low Temperature, Springer, Boston, MA, 17-46. https://doi.org/10.1007/978-1-4757-0190-6_2

[90] Liu, H.Q., Xiang, K.H., Li, H.J., Ran, C., Hu, J.H., Yao, T.S., Wang, J.J., Zhao, Z.M. and Wang, L.Y. (2013) Effect of Temperature on Larval, Pupation and Eclosion of Bactrocera minax (Enderlein). Chinese Horticulture Abstracts, 10, 13-14. [In Chinese]

[91] Hallman, G.J. and Blackburn, C.M. (2016) Phytosanitary Irradiation. Foods, 5, 1-10. https://doi.org/10.3390/foods5010008

[92] USDA (2015) Treatment Manual. https://www.aphis.usda.gov/import_export/plants/manuals/ports/downloads/treat ment.pdf

[93] IPPC (2015) International Standards for Phytosanitary Measures (ISPM) No 26: Establishment of Pest Free Areas for Fruit Flies (Tephritidae). http://www.fao.org/3/a-k7557e.pdf

[94] Duan, Y.P., Pan, Y.Q. and Wei, D.G. (2001) Preliminary Survey of Fruit Fly Occurrence in Shaanxi Province. Plant Quarantine, 4, 218-220. [In Chinese]

[95] Fang, Z.M. (2009) Occurrence and Control of Bactrocera minax. Journal of Zhejiang Citrus, 36, 31-35. [In Chinese]

[96] Lan, J., Wan, B.R., Li, K.S., Liao, G.X. and Li, C.R. (2009) The Attraction Effect of Fruit Fly Food Lure to Chinese Citrus Fly. Plant Quarantine, 23, 9-11. [In Chinese]

[97] Liang, R.C. (1988) Investigation on Species and Distribution of Fruit Fly in Guangxi. Plant Protection, 3, 25-30. [In Chinese]

[98] Liang, G.Q., Zhang, S.M. and Xu, W. (1989) The Notes of the Fruit Flies in South Parts of China and Two Newly Recorded Species. Acta Agriculturae Universitatis Jiangxiensis, 40, 14-20. [In Chinese]

[99] Liu, Z.C., Ao, Y.J. and Ding, D.K. (2010) Investigation on the Life Cycle of Bactrocera minax and Its Control Measures. Friend of Fruit Growers, 9, 36. [In Chinese]

[100] Zhou, H.Z., Xiang, Z.J. and Qin, X.J. (2009) Occurrence, Damage and Control of Bactrocera minax. Hubei Plant Protection, 111, 38-39. [In Chinese]

[101] Yu, L.M. (2007) Occurrence and Damage of Bactrocera minax. South China Agriculture, 5, 37-39. [In Chinese]

[102] Yang, S.M., Song, H.W., Huang, Y.S., Yang, Y.G. and Yu, S.H. (1997) Occurrence and Distribution of Quarantine Plant Pests in Qiandongnan City. Guizhou Agri- 
cultural Sciences, 25, 23. [In Chinese]

[103] Yang, J.X. and Hu, J.C. (2013) Overview of Occurrence and Control of Bactrocera minax in Yichang City in Year of 2012. Hubei Plant Protection, 136, 52-53. [In Chinese]

[104] Zhao, Q., Luo, Q.H., Xu, D.G., Yin, Z.P. and Gao, B. (2008) Preliminary Study on Lures Development of Bactrocera minax and Bactrocera tsuneonis. South China Fruits, 1, 33-34. [In Chinese]

[105] Zhang, K., Gao, X., Zhang, Y., Wang, Q.W., Liu, G., Huang, B.Q. and Pu, G.T. (2015) Investigation on the Preferable Host of Bactrocera minax in Hanzhong. Journal of Shaanxi Agricultural Science, 61, 49. [In Chinese]

[106] Ming, Y. (1985) Identification of Bactrocera minax and Bactrocera tsuneonis. Plant Quarantine, 4, 35-39. [In Chinese]

[107] Xia, S.W. and Song, X.P. (1985) Bactrocera tsuneonis Were Found on Citrus sinensis Osbeck in Luodian and Bijie, Guizhou. Plant Quarantine, 1, 47. [In Chinese]

[108] Liu, L., Zhou, Q., Song, A.Q. and You, K.X. (2014) Adult Oviposition and Larval Feeding Preference for Different Citrus Varieties in Bactrocera minax (Diptera:Tephritidae). Acta Entomologica Sinica, 57, 1037-1044 [In Chinese]

[109] Lu, H.X., Zhang, F.Y. and Mu, B.Z. (1998) Extraction and Testing of Sex Pheromones from Dacus citri (Chen). Journal of Hubei Agricultural College, 19, 32-34. [In Chinese] 